\title{
Interdisciplinary and evolutionary perspectives on managing the transition to a sustainable economy
}

\author{
Andreas Chai $^{1}{ }_{(\mathbb{D}}$
}

Published online: 24 February 2017

(C) Springer Science+Business Media New York 2017

\section{Introduction}

The recent 2015 United Nations Framework Convention on Climate Change established a legally binding and universal framework for reducing carbon emissions around the world. This landmark agreement has given renewed impetus to global efforts to tackle some of the fundamental challenges that inhibit the emission reductions. While much of this effort has thus far focussed on state-centred national adaptation strategies, non-state market adaptation processes are increasingly being recognized as central to both mitigation and adaptation strategies (Kinzig et al. 2013). For example, in some developed economies record levels of financial resources are flowing into clean energy initiatives while a considerable number of energy provider are divesting from coal-fired power plants.

It is therefore vital to rethink what kind of strategies can accelerate the pace of climate adaptation among the everyday consumers and producers whose interactions determine the pace and character of the global economy. There is an urgent need to find better ways to promote the voluntary adoption of sustainable practices among both consumers and producers alike. In the case of consumers, for example, the main type of policies being advocated are state-imposed tax and subsidy measures that rely on making 'green' consumption alternatives relatively cheap and 'brown' consumption activities relatively more expensive (Wagner 2006). These measures are only effective as long as consumers are sensitive to relative price changes and correspondingly alter their behaviour so as to minimize the cost of consumption. Several scholars have noted such measures could lead to the crowding out of the voluntary adoption of sustainable

\footnotetext{
$凶 \quad$ Andreas Chai

a.chai@griffith.edu.au

1 Griffith Business School, Gold Coast Campus Griffith University, Southport, QLD 4222, Australia
} 
consumption patterns (Frey and Jegen 2001; Claro 2007; Spash 2010). This suggests that solely relying on pecuniary incentives to achieve sustainable consumption patterns could in fact contribute to the lock-in of unsustainable consumption patterns, as consumers feel less intrinsically motivated and morally obliged to voluntary adopt sustainable consumption practices.

Beyond tax and subsidy measures, millions of dollars are spent every year by governments on 'soft' measures such as public information campaigns to promote the voluntary adoption of sustainable consumption practices among households. However many of these campaigns turn out to be relatively ineffective because of the so called 'value-action' gap (Chai et al. 2015). This refers to the great paradox that emerges when one compares public perceptions of climate change and its associated impact on the environment with the literature on consumption sustainability. In the former, survey after survey conducted around the world suggests that most individuals do accept that climate change is real and most express at least some level of concern about it e.g. (Nisbet and Myers 2007). On the other hand, while many do profess to be concerned about climate change and the state of the environment, there appears to be a yawning gap between these concerns and their propensity to act on these concerns by adopting sustainable consumption practices (Gifford et al. 2011). What are the social institutions that foster this gap and what type of new policies could deliver more effective outcome in terms reducing negative abatements and encouraging consumers to act on their environmental concern? To develop effective and evidence-based strategies that help consumers voluntarily act on the deep-seated climate change concerns, more interdisciplinary research is needed to understand the interplay between green public information campaigns, the adherence to social norms and consumer learning processes. In this regard, Evolutionary Economic approaches to studying consumer behaviour can be useful given its focus on the studying various way that consumer's knowledge and preferences adapt to changing market environments (Buenstorf and Cordes 2008; Woersdorfer and Kaus 2011; Witt 2011; Chai 2016; Baum 2016).

On the supply side, many economies continue to be heavily dependent upon fossil fuels. Not only does this provide a major challenge in the context of reducing carbon emissions but it also means that many economies lack the diversity in its power generation necessary to be resilient to unanticipated future developments in global energy markets. Low carbon emission technologies, such as wind and solar power generation, have been falling in cost as their adoption has increased. This has caused problems for coal generators and created a state of uncertainty in which capital investment strategies have been placed on hold (Byrnes et al. 2013). Inevitably, this has generated political pressure against policies designed to reduce carbon emissions which, in turn, has put investment strategies in the renewable sector on hold.

Given that it seems inevitable that renewables will become the lowest cost choice in some, but not all scenarios, what we are witnessing is 'creative destruction' in action (Molyneaux et al. 2013). So we can expect to see a significant reduction in the share of coal in power generation over the coming decades. How should policymakers manage this transition towards a changing mix of power generation? Globally, there have been many schemes introduced to subsidize investments in renewable energy and these have made sense when scale was low and unit costs high. However, parallel policies to assist with the exit of old and relatively inefficient coal generation plants have been 
less in evidence, particularly in Australia (see Nelson 2016; Foster and Bell 2017). This imbalance in policy application has tended to occur because of a narrow focus on carbon mitigation, using standard economic analysis, rather than on developing a system-wide strategy to facilitate the transition of the whole, highly-interconnected power system, using some of the analytical approaches developed by evolutionary economics (Foster 2011).

This special issue presents a number of papers that discuss the global challenges faced in managing the transition to a sustainable economy from an interdisciplinary perspective. The majority of these papers were presented at a 2015 workshop on "Managing the Transition to a Sustainable Economy: Some Insight from an Evolutionary Perspective" that was held in the run-up to the 21st Conference of the Parties (COP21) by Griffith University and the Global Change Institute (University of Queensland) in Brisbane, Australia. The aim of the workshop was to create a forum for interdisciplinary dialogue among economists, psychologists, engineers and environmental scientists studying climate change adaptation strategies.

The first two papers begin by delivering some empirical assessments of progress being made in the economy and among individuals in terms of adapting to climate change. Stern (2017) reviews the econometric literature studying the relationship between economic growth and emission levels across both developed and developing economies. From a psychological perspective, Bradley and Reser (2016) discuss recent trends in the extent to which individuals are psychologically adapting to climate change and how this process is critically mediated by natural and social environs.

The next three papers focus on the demand side and the behavioural barriers consumers face in adapting to climate change. Baum (2016) synthesizes contributions from economics, psychology and sociology to discuss how a richer conception of individual behaviour and its contextual determinants can yield useful insights for policymakers seeking to promote pro-environmental change among consumers. Earl (2016) adopts an evolutionary economic approach to analyse barriers that are rooted in the complex interconnections between choices that consumers must navigate on a daily basis. Finally, Ali (2016) focuses on the gem market and discusses the prospect of consumers viewing synthetically produced gems as environmentally friendly substitutes for rare earth mined gems.

The next two contributions discuss the policy challenges faced by in transitioning the Australian energy market towards low carbon forms of energy production. Foster and Bell (2017) discuss the impact on solar photo vatic feed-in tariffs and their impact on economic growth, social equity and the environment. Nelson (2016) outlines the policy principles that help achieve a smoother transition towards a decentralized and consumer-focused energy market. Finally, Potts et al. (2016) concludes this issue special issue by considering the co-evolution of market, state and the environment and how the interaction of these systems may contribute (or inhibit) the transitions towards a sustainable economy.

The editors would like to express their thanks to all referees involved in the reviews of these articles. We also extend our thank to sponsors of the 2015 workshop, including The Global Change Institute, The Griffith Asia Institute, The Griffith Centre for Sustainable Enterprise and The Griffith Climate Change Response Program. 


\section{References}

Ali, S. H. (2016). The ecology of diamond sourcing: From mined to synthetic gems as a sustainable transition. Journal of Bioeconomics. doi:10.1007/s10818-016-9241-8.

Baum, C., \& Gross, C. (2016). Sustainability policy as if people mattered: Developing a framework for environmentally significant behavioral change. Journal of Bioeconomics. doi:10.1007/ s10818-016-9238-3.

Bradley, G \& Reser, J. (2016). Adaptation processes in the context of climate change: A social and environmental psychology perspective. Journal of Bioeconomics. doi:10.1007/10818-016-9231-x.

Buenstorf, G., \& Cordes, C. (2008). Can sustainable consumption be learned? A model of cultural evolution. Ecological Economics, 67(4), 646-657.

Byrnes, L., Brown, C., Foster, J., \& Wagner, L. D. (2013). Australian renewable energy policy: Barriers and challenges. Renewable Energy, 60, 711-721.

Chai, A. (2016). Tackling Keynes' question: A look back on 15 years of learning to consume. Journal of Evolutionary Economics, 1-21. doi:10.1007/s00191-016-0455-7.

Chai, A., Bradley, G., Lo, A., \& Reser, J. (2015). What time to adapt? The role of discretionary time in sustaining the climate change value-action gap. Ecological Economics, 116, 95-107.

Claro, E. (2007). Exchange relationships and the environment: The acceptability of compensation in the siting of waste disposal facilities. Environmental Values, 16, 187-208.

Earl, P. (2016). Lifestyle changes and the lifestyle selection process. Journal of Bioeconomics. doi:10.1007/ s10818-016-9212-0.

Foster, J., \& Bell, W. P. (2017). Using solar PV feed-in tariff policy history to inform a sustainable flexible pricing regime to enhance the diffusion of energy storage and electric vehicles. Journal of Bioeconomics. doi:10.1007/s10818-016-9240-9.

Foster, J. (2011). Energy, aesthetics and knowledge in complex economic systems. Journal of Economic Behavior \& Organization, 80(1), 88-100.

Frey, B. S., \& Jegen, R. (2001). Motivation crowding theory. Journal of Economic Surveys, 15, 589-611.

Füssel, H. M., \& Klein, R. J. (2006). Climate change vulnerability assessments: An evolution of conceptual thinking. Climatic Change, 75(3), 301-329.

Gifford, R., Kormos, C., \& McIntyre, A. (2011). Behavioral dimensions of climate change: Drivers, responses, barriers, and interventions. Wiley Interdisciplinary Reviews: Climate Change, 2, 801-827. doi: $10.1002 /$ wcc. 143 .

Kinley, R. (2017). Climate change after Paris: From turning point to transformation. Climate Policy, 17(1), $9-15$.

Kinzig, A. P., Ehrlich, P. R., Alston, L. J., Arrow, K., Barrett, S., Buchman, T. G., Daily, G. C., Levin, B., Levin, S., Oppenheimer, M., Ostrom, E., \& Saari, D. (2013). Social norms and global environmental challenges: The complex interaction of behaviors, values, and policy. BioScience, 63(3), 164-175.

Molyneaux, L., Froome, C., Wagner, L., \& Foster, J. (2013). Australian power: Can renewable technologies change the dominant industry view? Renewable Energy, 60, 215-221.

Moss, R. H., Edmonds, J. A., Hibbard, K. A., Manning, M. R., Rose, S. K., Van Vuuren, D. P., Carter, T. R., Emori, S., Kainuma, M., Kram, T., Meehl, G. A., Mitchell, J. F., Nakicenovic, N., Riahi, K., Smith, S. J., Stouffer, R. J., Thomson, A. M., Weyant, J. P., \& Wilbanks, T. J. (2010). The next generation of scenarios for climate change research and assessment. Nature, 463(7282), 747-756.

Nelson, T. (2016). Redesigning a 20th century regulatory framework to deliver 21 st century energy technology. Journal of Bioeconomics. doi:10.1007/s10818-016-9216-9.

Nisbet, M. C., \& Myers, T. (2007). The polls—-trends: Twenty years of public opinion about global warming. Public Opinion Quarterly, 71, 444-470. doi:10.1093/poq/nfm031.

Potts, J, Almudi, I. \& Fatas-Villafranca, F. (2016). Utopia competition: A new approach to the microfoundations of sustainability transitions. Journal of Bioeconomics, 1-21.

Spash, C. L. (2010). The brave new world of carbon trading. New Political Economy, 15, 169-195.

Stern, D. (2017). The environmental Kuznets curve after 25 years. Journal of Bioeconomics. doi:10.1007/ s10818-017-9243-1.

Wagner, J. (2006). On the economics of sustainability. Ecological Economics, 57, 659-664.

Witt, U. (2011). The dynamics of consumer behavior and the transition to sustainable consumption patterns. Environmental Innovation and Societal Transitions, 1(1), 109-114. 
Woersdorfer, J. S., \& Kaus, W. (2011). Will nonowners follow pioneer consumers in the adoption of solar thermal systems? Empirical evidence for northwestern Germany. Ecological Economics, 70(12), 2282-2291. 